\title{
TUBERCULOUS PERICARDITIS*
}

\author{
BY \\ A. A. FITZGERALD PEEL \\ From the Cardiac Department Victoria Infirmary, Glasgow
}

Received June 28, 1948

The incidence of tuberculous pericarditis in this country seems to have been underestimated in the past. The role of tuberculosis as one of the ætiological factors in chronic constrictive pericarditis is being increasingly recognized (White, 1935; Sellors, 1946); yet relatively few studies of the onset or acute stage of the disease have been published, and the majority of these hail from overseas.

\section{Incidence of Tuberculous Pericarditis}

Osler (1893) analysed 1000 autopsies, of which 215 were cases of tuberculosis and 7 had tuberculous pericarditis, giving an incidence of 0.7 per cent in the U.S.A. Norriss (1911), also in the U.S.A., found 1780 cases of tuberculosis in 7219 consecutive autopsies; 82 of the tuberculous cases had pericarditis, an incidence of 1.1 per cent. As compared with these figures Suzman found an incidence of 0.4 per cent in autopsy records at Guy's hospital; 1500 autopsies yielded 102 cases of tuberculosis, of whom 6 had pericarditis. American writers agree in stating that the condition is more frequent in coloured patients than in whites; this, no doubt, has helped to enhance the impression that it is " rare in Europeans" (White, 1935). High susceptibility appears to extend also to coloured African races, for Heimann and Binder (1940) succeeded in collecting 31 examples in Bantu natives in Johannesburg.

Ellman (1945) published a series of 6 cases and suggested that the disease is less infrequent in this country than had hitherto been supposed. Autopsy statistics may be misleading because tuberculous pericarditis sometimes undergoes complete resolution (Ellman, 1945; also Cases 3 and 6 of present series) or because the tuberculous nature of a chronic pericarditis is not always recognizable histologically on examination of excised pericardium or autopsy material. White (1935) had a case in which pericardium excised at operation showed nonspecific fibrosis; the patient died shortly after the operation, and at autopsy tubercles were found in the remainder of the pericardium. Dr. T. Semple (personal communication) had a patient with constrictive pericarditis whose excised pericardium was reported histologically as showing non-specific fibrous thickening; four months after the operation the patient developed tuberculosis of an elbow joint. It is certain, therefore, that in addition to the recognized cases of constrictive pericarditis, others are tuberculous in origin despite a non-specific histological picture. Furthermore failure to find tubercle bacilli in a pericardial effusion should not be allowed to cast doubt on a diagnosis of tuberculous pericarditis if there is other evidence, clinical or radiological, pointing to a tuberculous ætiology; Fine and Katz (1944) report an instance of primary tuberculosis of the pericardium in which the pericardial fluid was negative on guinea-pig inoculation; nevertheless the patient died a month later from miliary tuberculosis with meningitis, and tuberculous pericardial thickening was found at autopsy.

Excluding 3 seen in consultation on a single occasion, 8 cases of tuberculous pericarditis have been under my personal observation during the past 13 years; 7 were males; 3 were in hospital during the single year 1947 . The incidence would therefore seem to be considerably greater in this country than has previously been suspected. The youngest was an infant of 18 months; three were boys aged 11,14 , and 15 ; three were men aged 23,27 , and 43 ; and the woman was aged 20 . All writers agree that the incidence is considerably greater in males than in females. Harvey and Whitehill (1937) found 90 per cent males in a series of 95 cases admitted to the Johns Hopkins Hospital during a period of 45 years. Their maximum age incidence was between 20 and 30

* This article includes material used in communications to the British Cardiac Society, May 1948, and the 111 Inter-American Cardiological Congress, June 1948. 
(25 per cent of cases), but every decade in life was represented and several patients were over 50 .

\section{Stage at which Pericarditis Develops}

Paget (quoted by Ellman, 1945) has stated that most cases arise in the stage of early dissemination following the primary infection. Harvey and Whitehill's findings (1937) are consistent with this view; of their 37 bacteriologically proved cases, only one had previous hæmoptysis. The present series amply bears out Paget's suggestion. Two patients (Cases 1 (Fig. 1-3) and 2 (Fig. 4-6) ) developed pericarditis in the presence of an active primary Ghon lesion with hilar gland involvement; one of them had early secondary infiltration as well. Two (Cases 3 (Fig. 7-9) and 7) had pericarditis accompanying an apparently primary tuberculous pleurisy. Three (Cases 4, 6, and 8) occurred in the absence of any demonstrable lung or pleural lesion. In Case 4 the ætiology was obscure at the onset of his acute attack, but a pleural effusion appeared after a month; pericardial constriction followed and the tuberculous ætiology was proved by histological examination of excised pericardium nine months later. Case 6 was never proved tuberculous beyond doubt; but his initial pericarditis was followed by a right-sided pleural effusion after five months, and by a left-sided pleural effusion with recrudescent pericarditis four months later. Case 8 is recent, suspected though as yet unproved, and still under observation. Only once (Case 5) did pericarditis complicate pulmonary disease of longer standing; this was a male, aged 43 , with an old calcified lesion

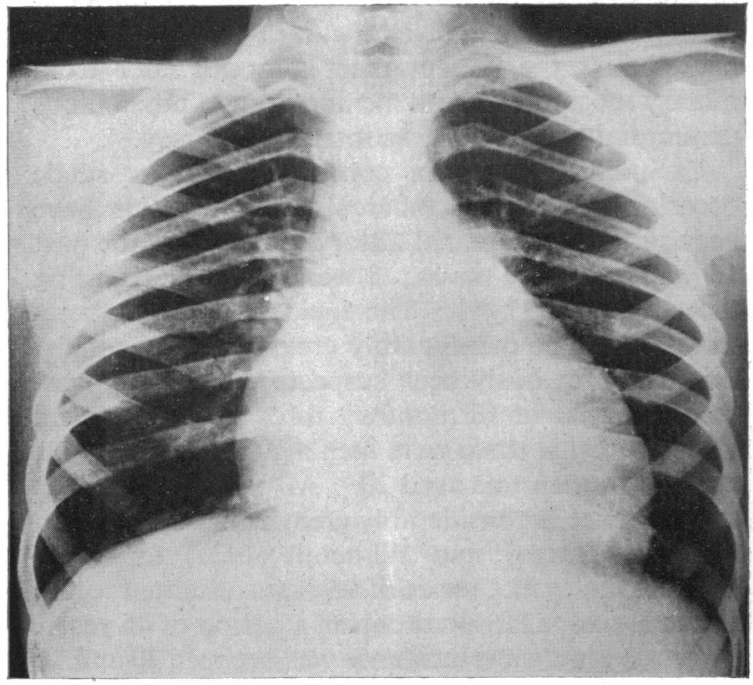

FIG. 1-Case 1. Teleradiogram, 13/12/47. Pericardial effusion with Ghon focus. at his right apex: he developed a pleural effusion with tubercle bacilli in the fluid and in his sputum, though X-ray failed to reveal signs of activity of his pulmonary lesion; four months later, when he was regarded as convalescent and due for discharge from hospital, a pericardial effusion suddenly developed; the pericardial fluid contained tubercle bacilli.

\section{Mode of Infection of Pericardium}

Riesman (1901) classified tuberculous pericarditis into four groups: (1) with generalized miliary tuberculosis, (2) with serous membrane tuberculosis, (3) by extension from neighbouring foci (regarded by him as the commonest) and (4) primary. Most writers question the existence of anatomically primary tuberculosis of the pericardium. Clinically primary pericardial tuberculosis has been regarded as uncommon in the past; Clarke (1929) stated that careful search revealed only 11 such reported cases in which the diagnosis could not be questioned; Fine and Katz (1944) found only one case reported in children under 15 (by Blatt and Greengard, 1928); they add one of their own. The revival of interest in pericardial constriction, brought about in recent years by the possibilities of surgical treatment, has led to the general belief that clinically primary cases must be less infrequent than these reports would suggest.

No less than three in the present series (Cases 4, 6 , and 8) fall into the category of " clinically primary "; yet it seems almost certain that they are, in fact, secondary to tuberculosis of the mediastinal

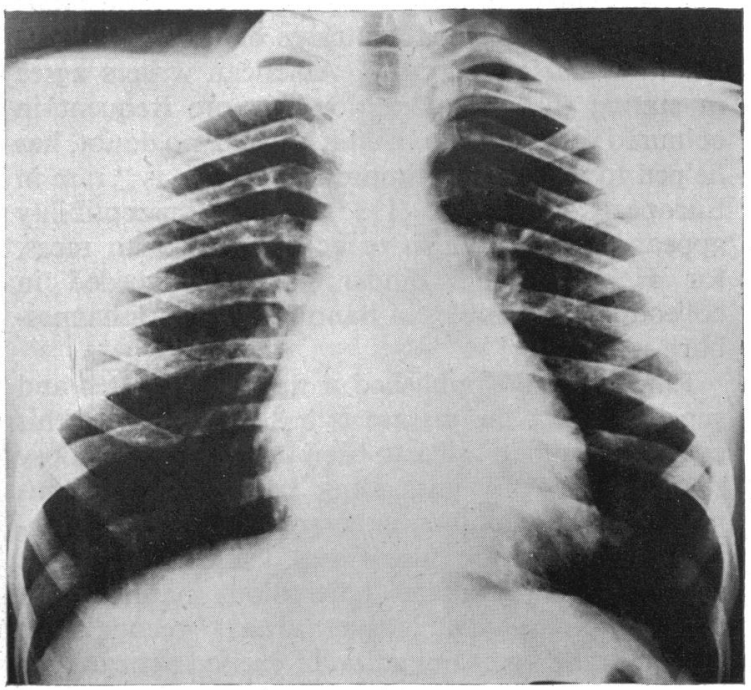

Fig. 2-Case 1. Teleradiogram, 20/1/48. Effusion largely absorbed; Ghon focus persists. 

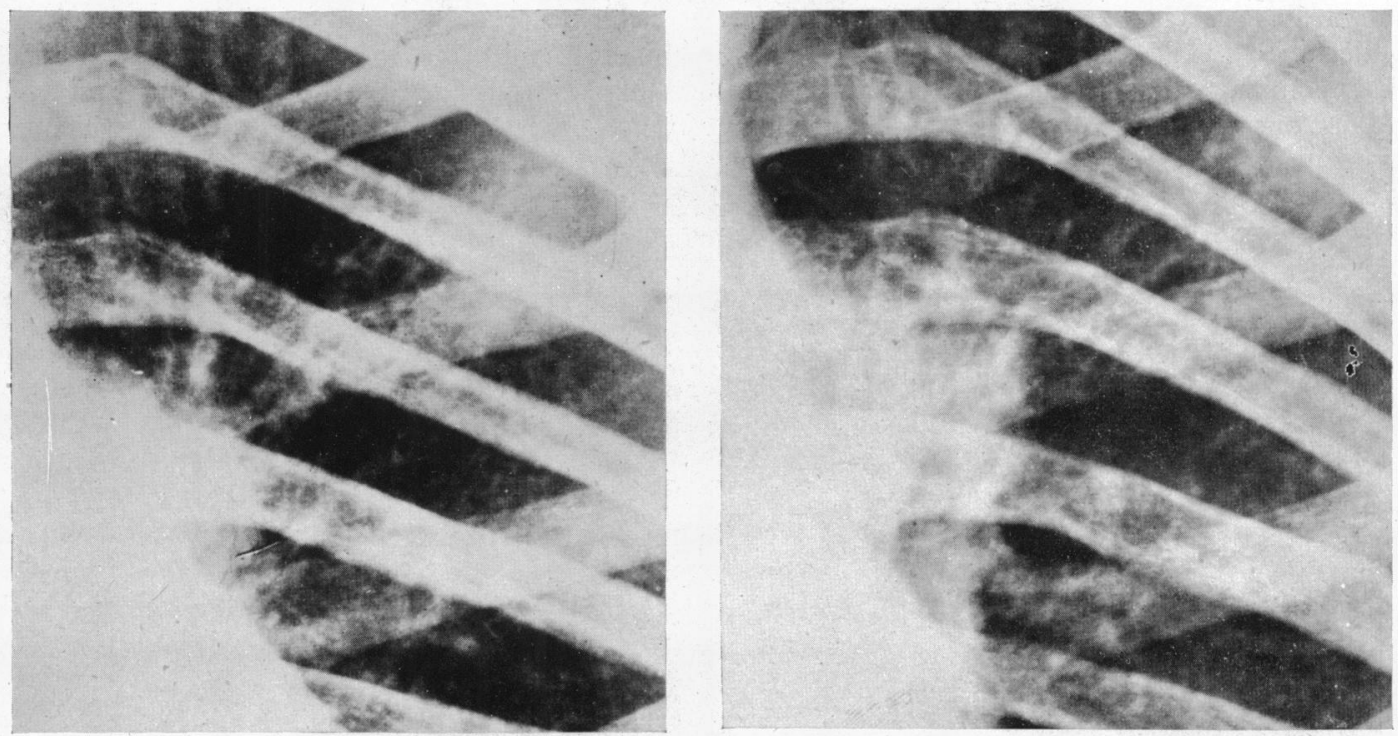

Fig. 3-Case 1. Teleradiograms. Enlarged view of Ghon focus with hilar glands on 13/12/47 and 16/2/48.

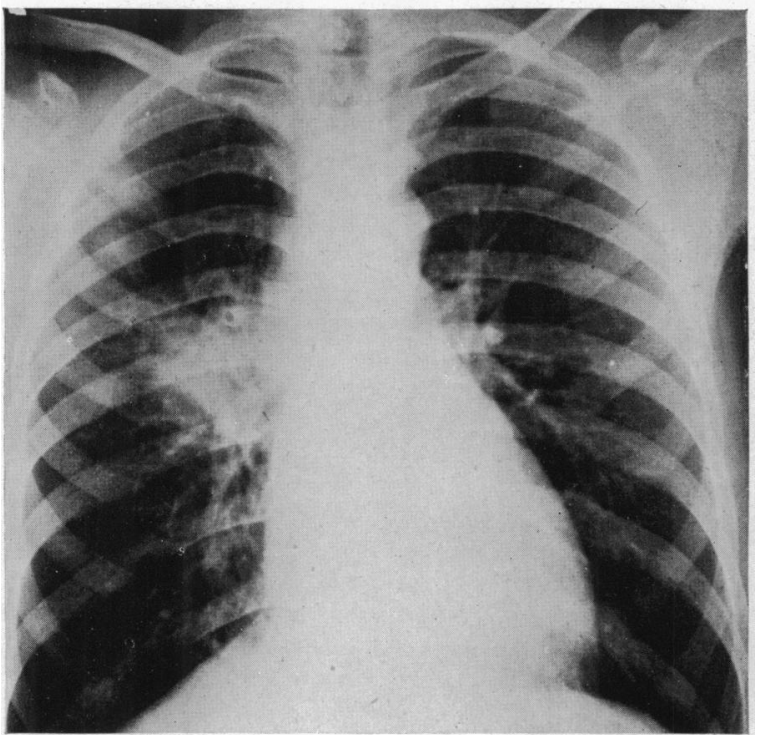

Fig. 4-Case 2. Teleradiogram, 28/11/47. P-A view.

lymph glands, from which the pericardium has become infected by extension. Failure to visualize enlarged mediastinal glands radiologically cannot be held to exclude tuberculosis of these glands. In the two cases where pericarditis accompanied an active primary Ghon lesion, the radiological picture strongly suggests direct extension from hilar glands as the probable route of infection (Fig. 3 and 6).

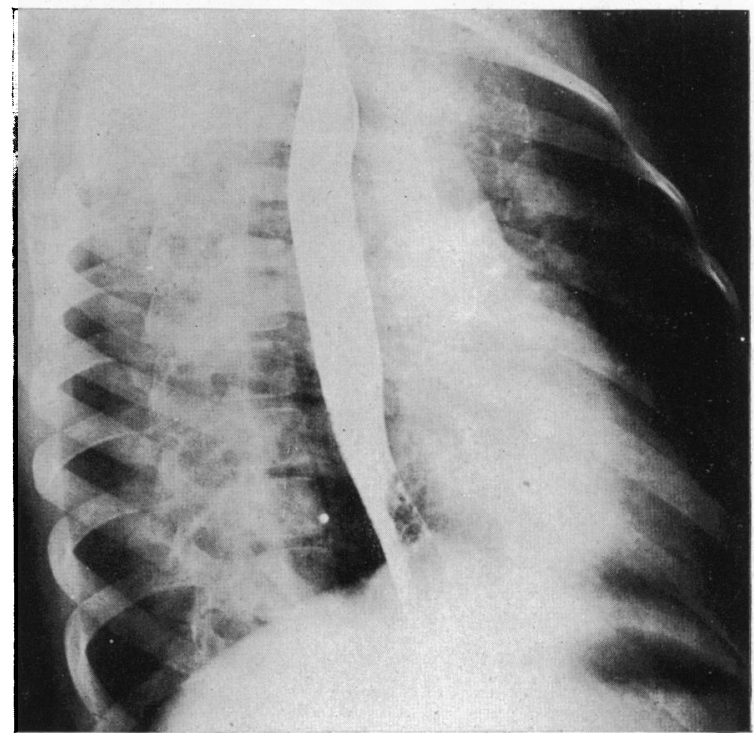

Fig. 5-Case 2. Teleradiogram, 20/1/48. Right oblique view.

In another patient (Case 3) where pericarditis accompanied a right-sided pleural effusion, serial $\mathrm{X}$-rays revealed transient enlargement of the glands in the left hilum (Fig. 7). Heimann and Binder (1940) found tuberculous mediastinal glands in all their cases but pulmonary lesions were present only in 16 of the 28 autopsies. Harvey and Whitehill (1937) and Hannesson (1941) also regard extension 
from mediastinal glands as the most important route of infection.

While miliary tubercles may form in the pericardium during the course of miliary tuberculosis, this form of pericarditis is clinically unimportant; the course of the disease is not modified. It must be borne in mind that tuberculous pericarditis can

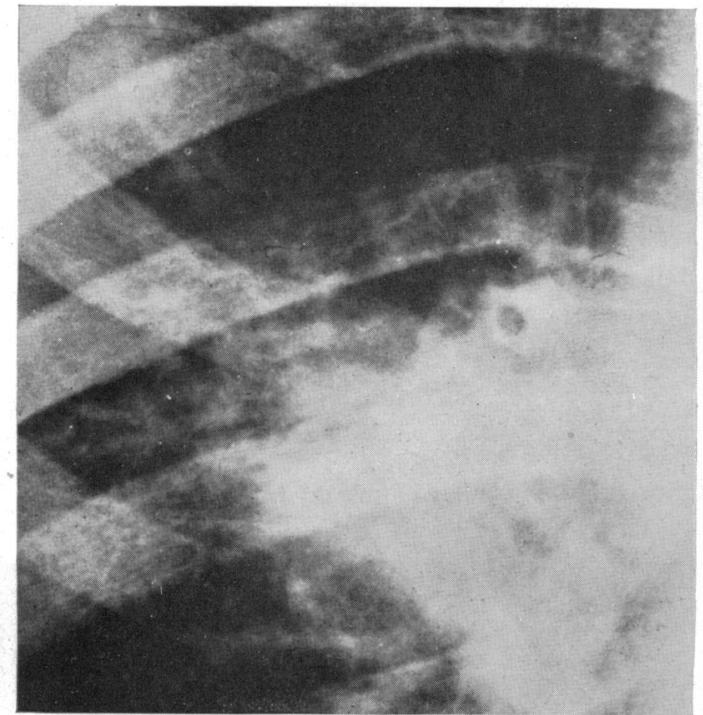

Fig. 6-Case 2. Teleradiograms. Enlarged view of Ghon focus and secondary infiltration on 22/11/47 and $25 / 4 / 48$.
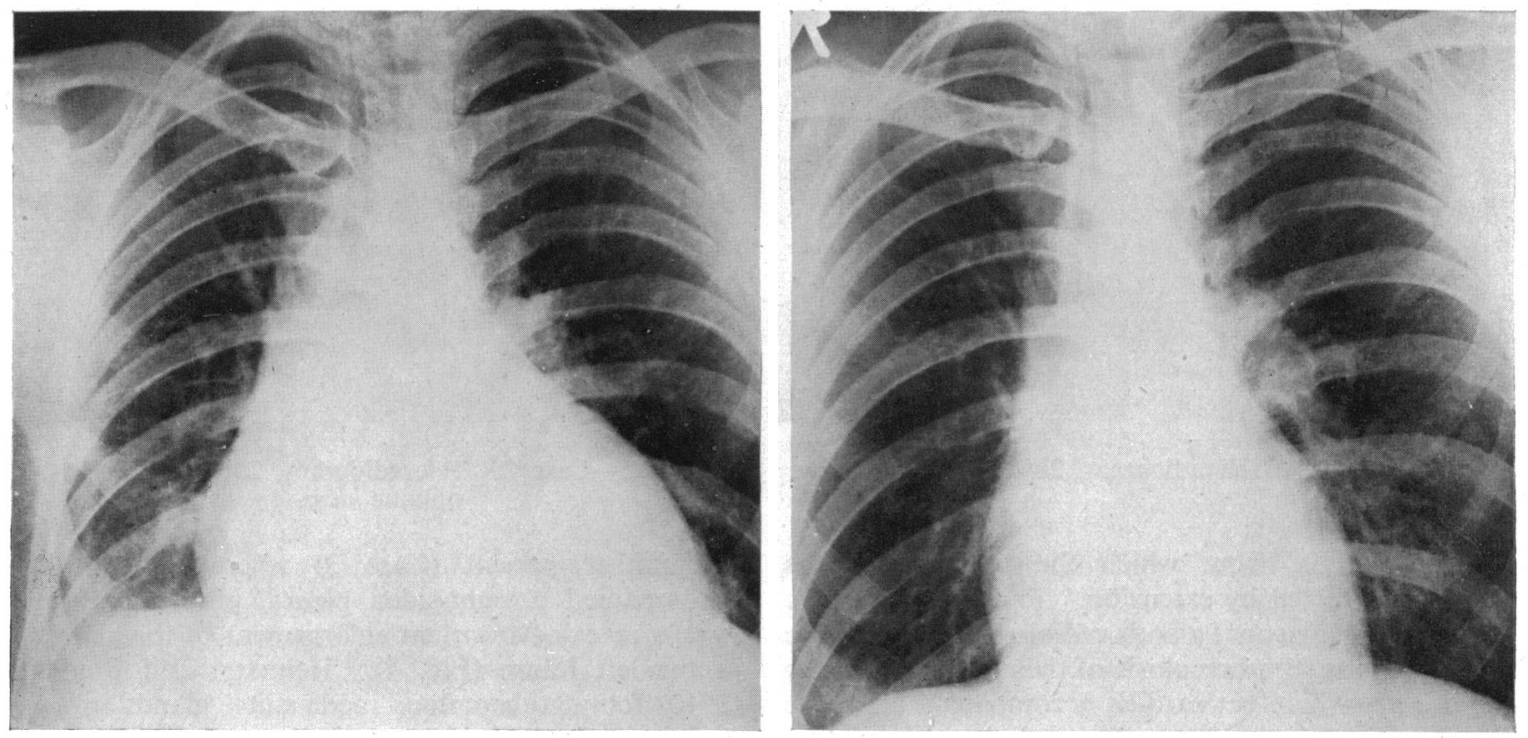

Fig. 7-Case 3. Teleradiogram, 1/5/47, with pericardial and right pleural effusions. terminate in miliary tuberculosis; Heimann and Binder (1940) had several cases in which miliary tuberculosis followed tuberculous pericarditis, but they failed to find a single instance in which pericarditis was secondary to miliary tuberculosis; they were dealing with cases of "clinically important" pericarditis.

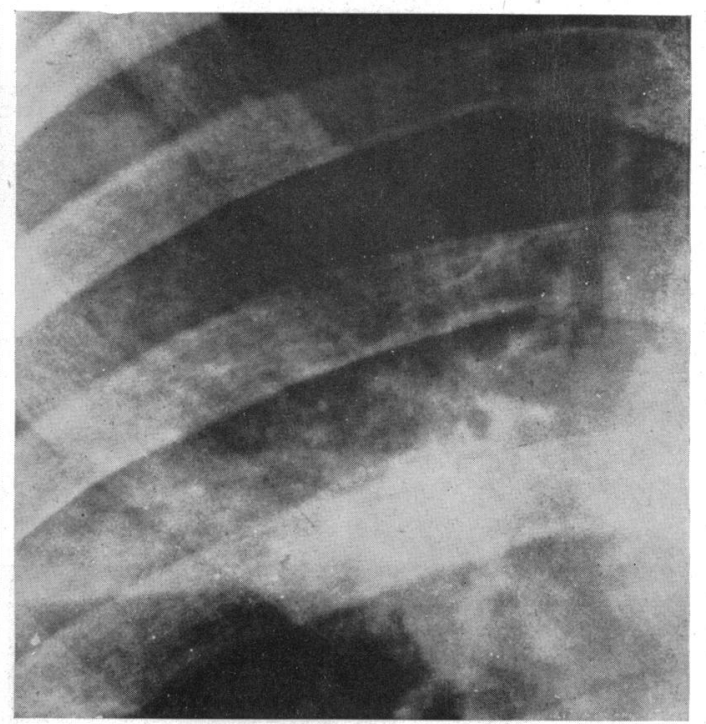
4/48.

Fig. 8-Case 3. Teleradiogram, 19/5/47, with left hilar enlargement. 


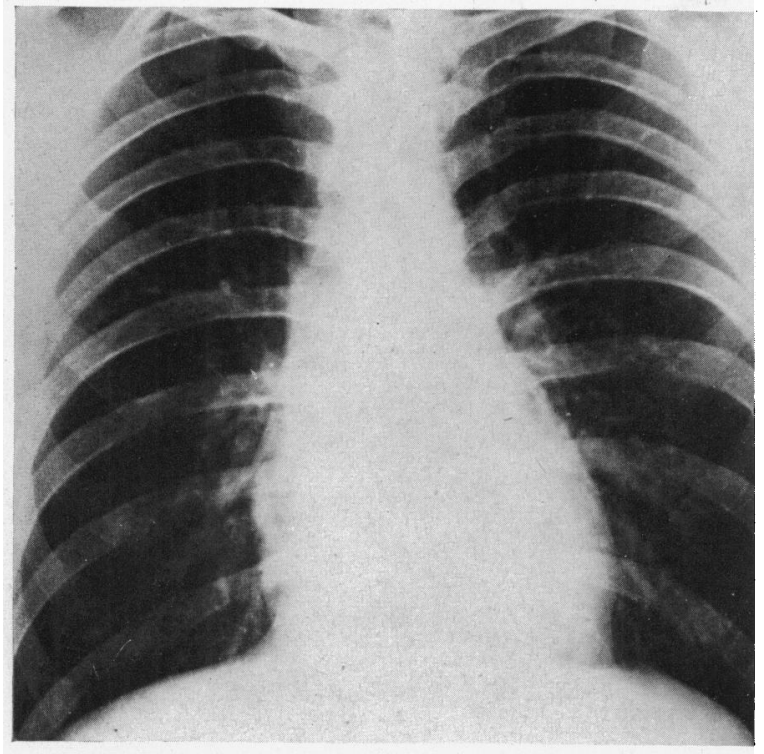

FIG. 9-Case 3. Teleradiogram, 8/9/47, showing complete resolution.

\section{SYMPTOMATOLOGY}

American writers (Harvey and Whitehill, 1937; Hannesson, 1941) differentiate two groups of cases, in one of which the clinical features suggest acute tuberculosis or other acute infection; pericarditis is an incidental finding and is " clinically unimportant." Only one case in the present series falls into this group; this was a young woman of 20 , a member of the W.A.A.F. who was admitted to an E.M.S. hospital with fever, tachycardia, flushing, sweating, and signs of a large right-sided pleural effusion from which tubercle bacilli were recovered; there were no cardiac or circulatory symptoms, pericardial friction and effusion being found incidentally. It seems likely that, under conditions obtaining in Great Britain, such cases are more likely to be encountered in fever hospitals or sanatoria than in general hospitals.

The second group is that in which the pericarditis is "clinically important" that is to say the clinical features point to cardiac disease and pericarditis is the presenting symptom. One of the most striking characteristics of this group is the relative insignificance of constitutional symptoms. Almost all writers comment on this (Harvey and Whitehill, 1937; Hannesson, 1941; Suzman, 1943; Barrett and Cole, 1944; Ellman, 1945); and it has been noteworthy in the present series. Loss of weight and night sweats have been conspicuous by their absence. Case 2 was afebrile (Fig. 10); while in Case 3 fever was virtually absent (Fig. 11), a tempera- ture of $99^{\circ} \mathrm{F}$. having been recorded only on four occasions during the course of the illness. In the absence of cardiac tamponade the pulse rate rarely exceeds 110 while the sleeping pulse rate has usually been between 80 and 95 . Thus Case 1 who had fever (Fig. 12), friction, pericardial effusion, cardiographic evidence of myocarditis, and radiological evidence of an active Ghon lesion, had a sleeping pulse rate between 90 and 95 with a waking pulse rate between 100 and 110 ; Case 3 with friction and effusion but no fever had a pulse rate between 60 and 70 ; in Case 2 the pulse rate remained unaltered (sleeping pulse 80 , waking pulse 90 to 100) when pericardial friction appeared. In this respect tuberculous pericarditis presents a marked contrast to rheumatic pericarditis. Pallor was present in the four children in the series, the facial appearance being similar to that in rheumatic carditis; but despite the pallor there was remarkable absence of lassitude - the patients being bright, active and alert, almost euphoric in their insistence that they felt nothing wrong at times when they were febrile with friction or signs of effusion. Appetite has generally remained unimpaired.

Subjective symptoms, when present, have consisted of præcordial pain (Case 3), of circulatory embarrasment from cardiac tamponade (Case 5), of pressure cough (Case 1), or have been attributable to a coincident pleurisy (Case 7).

An interesting physical finding has been the persistence of loud pericardial friction over the entire præcordial area in two instances (Cases 1 and 3 ) in the presence of a moderately large effusion. This feature has previously been noted by Harvey and Whitehill (1937) and by Ellman (1944), though no explanation of such an apparent anomaly has been attempted. In both cases the effusion has seemed of sufficient size to ensure separation of the parietal and visceral layers of the pericardium (see Fig. 1 and 7), and it seems likely that the sound has been produced in the parietal layer itself. In the chronic constrictive stage of tuberculous pericarditis the parietal layer is usually much thickened, often to a considerably greater extent than the visceral layer; it seems reasonable to suppose that this layer will be the seat of inflammatory thickening in the acute stage also. In these circumstances the alternating tension and relaxation which must be communicated to the parietal layer through the inelastic fluid content of the sac at each cardiac diastole and systole, may perhaps be responsible for the production of the friction sound.

\section{MYOCARDiAL LeSIONS}

With the exception of Heimann and Binder (1940), who found myocardial lesions in 10 of their 28 


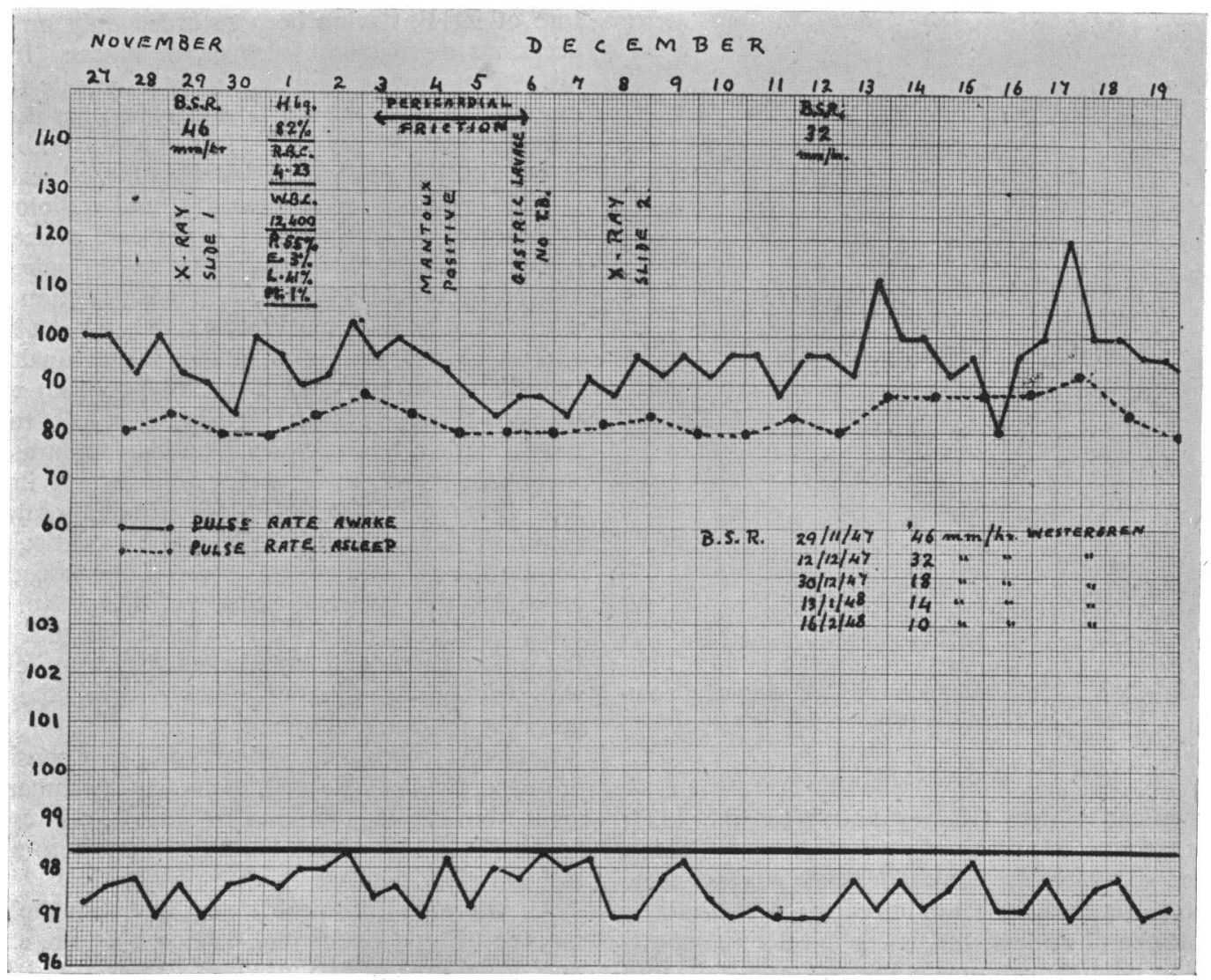

Fig. 10.-Case 2. Temperature and pulse chart.

autopsies in Bantu natives (36 per cent), most writers regard myocardial tuberculosis as rare. Thus Harvey and Whitehill (1937) encountered only two instances of infiltration of the myocardium apart from the presence of miliary tubercles in one patient with miliary tuberculosis; the left auricle was involved in one, the ventricles in the other. One patient in the present series (Case 1) had cardiographic evidence of myocardial involvement; there was M-shaped notching of QRS in lead CR 2 suggesting a lesion of the right bundle branch (Fig. 13): this persisted for a month, then gradually disappeared; in addition, there was $T$ wave inversion in leads I, II, CR 2, CR 4, and later CR 6; this likewise persisted for fully a month after the effusion had completely absorbed.

Harvey and Whitehill found that arrhythmias were confined to patients who had received digitalis; auricular fibrillation occurred in two, latent heart block in two, partial heart block once, complete heart block once, and nodal rhythm once. Case 5 of the present series had auricular fibrillation for a time; he had previously been treated with digitalis and mercurial diuretics. None of the remaining patients received digitalis; and none showed any arrhythmia while under my observation, though one was stated by his doctor to have had cardiac irregularity (the type of which was not specified) at the onset of his illness (Case 6).

\section{ENDOCARDIAL LESIONS}

Tubercles have been found in the endocardium and valves in some recorded cases, but there is no evidence to suggest that chronic valvular disease ever results (Hannesson, 1941); thus tuberculosis was found only once in a series of 300 cases of mitral stenosis. Conversely White states that mitral stenosis is extremely rare in cases of tuberculosis. A previous history of rheumatism was unusual in Harvey and Whitehill's series (1937); three of their patients gave a vague story of joint pains from 6 to 11 months before the onset of their present illness; but the description was not that of a typical rheumatic polyarthritis, and in no instance had there been 


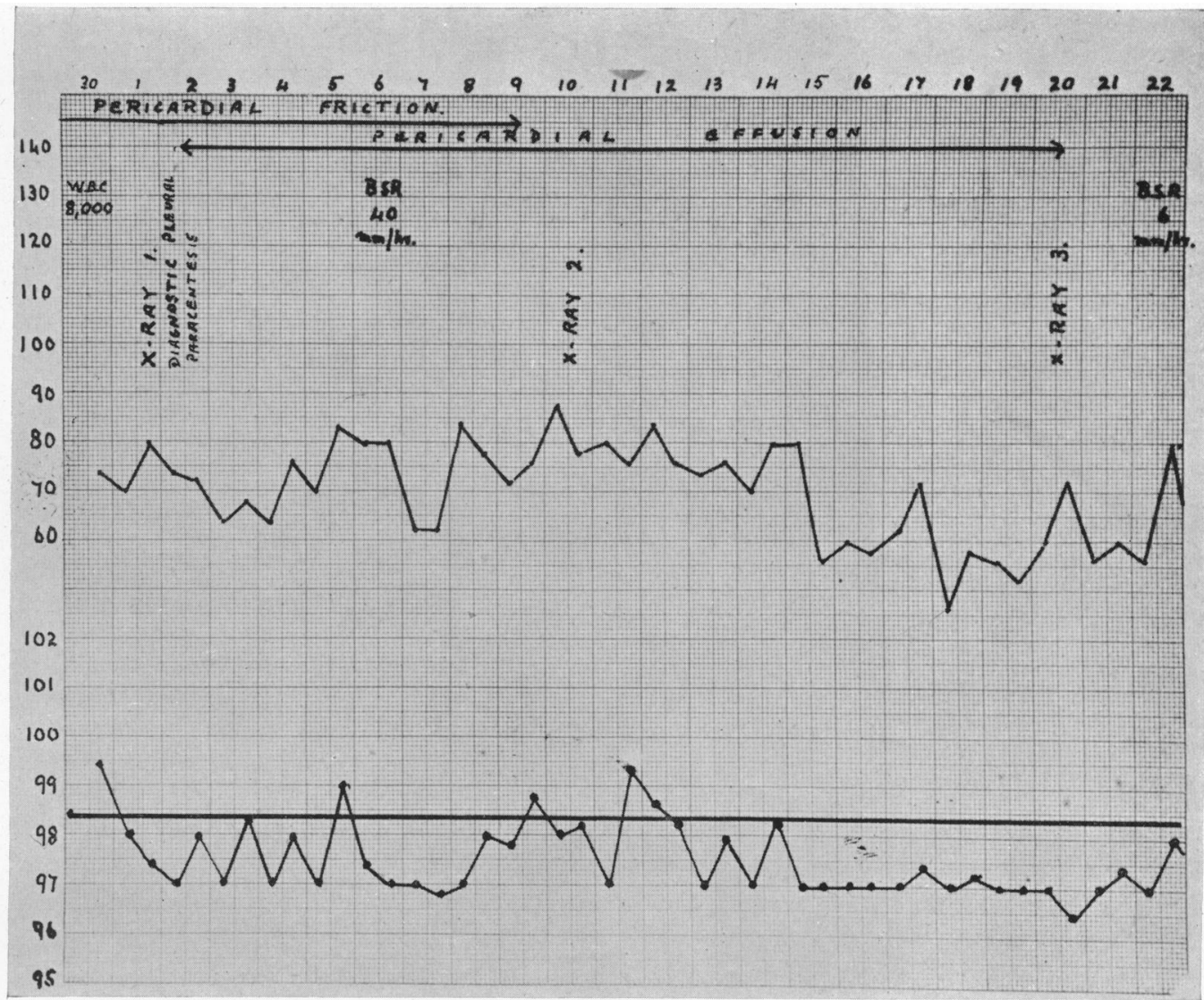

Fig. 11.-Cáse 3. Temperature and pulse chart.

symptoms of myocardial insufficiency. 'All writers are in substantial agreement in regarding absence of valvular lesions as an important diagnostic point in the differentiation of tuberculous and rheumatic pericarditis.

Errors in diagnosis might arise from the fact that pericardial thickening can produce exaggeration of the auricular impression on the œsophagus similar to that seen in mitral stenosis (Rubin, 1948); but clinical signs of the valvular lesion are absent. Pericardial effusion, at one stage during its absorption, appears to be capable of producing a similar radiological picture. Thus Case 3, whose first X-ray showed a fairly large pericardial effusion, was reported as a case of mitral stenosis by the radiologist when his second X-ray was examined; there was, however, never any clinical justification for this diagnosis, and the radiological signs that simulated mitral stenosis had vanished completely a month later. Case 4 was also regarded incorrectly as having mitral stenosis by two independent radiologists.
In these circumstances Case 2 of the present series is all the more remarkable, and appears to be unique. This boy had atypical rheumatism at the age of 11 ; there was no sore throat and pains were confined to the metatarso-phalangeal and hip joints. Three years later he had a second attack identical with the first, but on this occasion endocardial murmurs were recognized in the mitral area. He was referred to the outpatient department after 8 weeks when he had a mid-diastolic mitral murmur with slight prominence of the left auricle and the pulmonary artery radiologically. There was also an active primary Ghon lesion with hilar gland enlargement on the right side, and early secondary infiltration of the base of the right upper lobe. Pericarditis appeared a week later, while he was under observation in hospital; it was not accompanied by any disturbance in temperature or pulse rate, and symptomatically it resembled a tuberculous as opposed to a rheumatic pericarditis; it occurred at a time when there was ample evidence of active tuberculosis (radiological, 
skin reactions, and lymphocytosis), while there had been no symptoms of active rheumatism for two months. There can be little doubt that the pericarditis was tuberculous. Six months afterwards, the classical presystolic murmur of mitral stenosis was present. The nature of the endocarditis is open to greater doubt. It might be argued that the atypical rheumatism was in reality an example of tuberculous rheumatism, and that the endocarditis was likewise tuberculous. However the first attack of joint pains had occurred three years previously, and the mitral stenosis was more consistent with a 3-year than an 8-week history; whereas the Ghon lesion was undoubtedly his primary tuberculous infection and is unlikely to have been present for more than a few weeks. I believe therefore, that this boy had a rheumatic endocarditis with tuberculous pericarditis secondary to his Ghon lesion.

With the exception of the foregoing case, signs of endocarditis were never found in the series; and none of the remaining patients gave a history of rheumatic manifestations.

\section{Course and Prognosis}

The presence or absence of tubercle bacilli in the pericardial fluid is of the utmost importance in prognosis. Harvey and Whitehill (1937) had a mortality of 83 per cent in their 37 bacteriologically proved cases; Blalock and Levy (1937) also quote a mortality of 83 per cent in a series of 24 bacteriologically proved cases. Contrasting with this, the death rate was only 6 per cent in Harvey and Whitehill's 34 bacteriologically negative cases, which resembled their proved cases in all other respects. None of the latter group showed signs of pericardial constriction on discharge from hospital. Seventeen were followed for periods varying from six months to seven years: one developed signs of adhesive mediastinitis with portal obstruction seven years after having made an apparently complete recovery; 


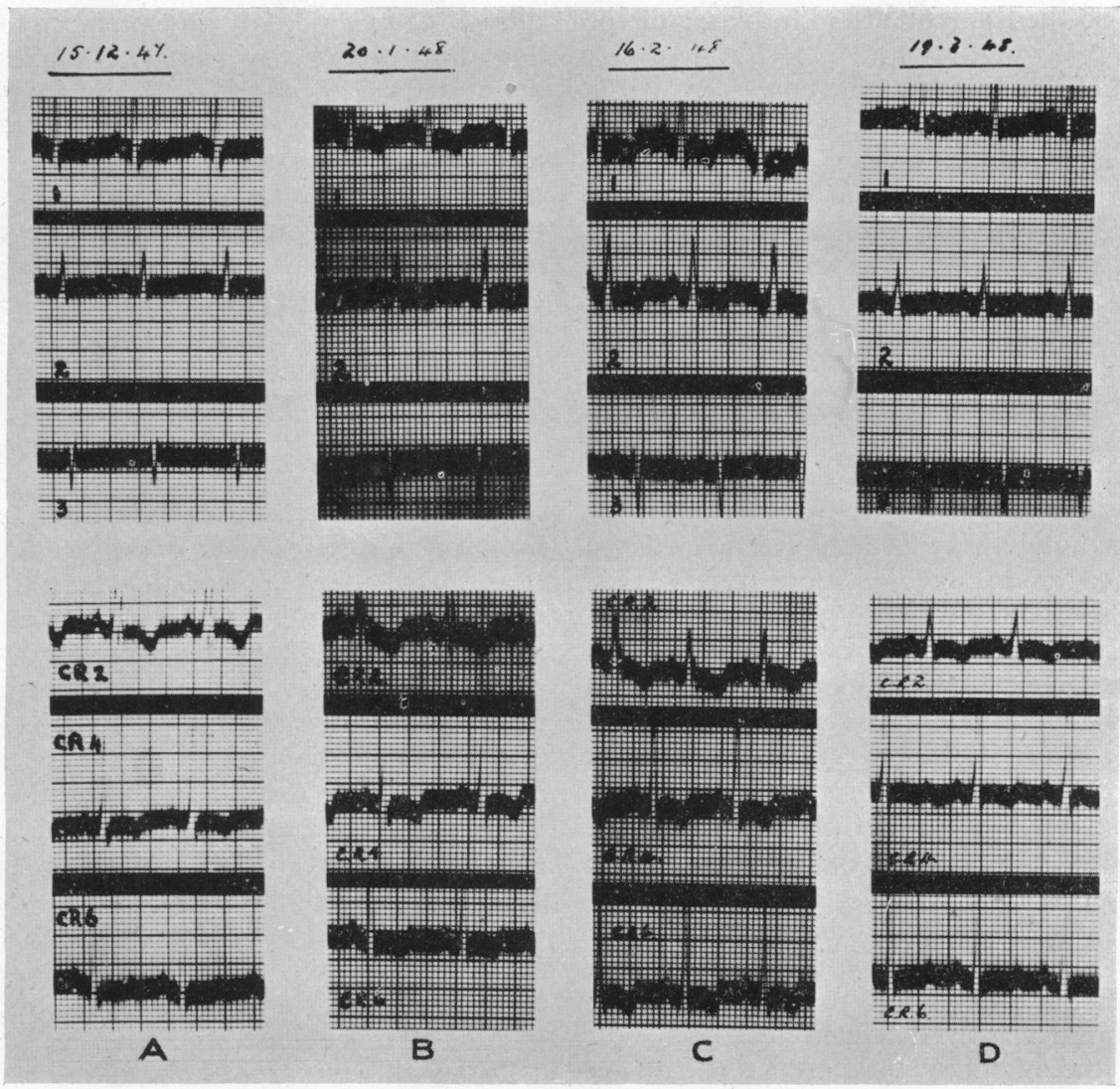

Fig. 13.-Case 1. Serial electrocardiograms. (A) $15 / 12 / 47$. (B) $20 / 1 / 48$. (C) $16 / 2 / 48$. (D) $19 / 3 / 48$.

two developed tuberculous lesions elsewhere; nine remained well. Ellman (1945) also believes that the disease may become arrested during its course, and that some cases result in a cure at the stage when the effusion has been absorbed.

Two cases in the present series were bacteriologically proved, tubercle bacilli being recovered from the pericardial fluid in one that proved fatal in 12 months, and from the pleural fluid in one whose subsequent fate is unknown. Of the remaining six cases one died, two have apparently recovered (observed for 3 years and 1 year respectively) while three are recent, two of them seemingly recovering.

The various courses which the disease may pursue are well illustrated in the series. In its fully-fledged form it passes through (1) a dry stage, (2) a stage of effusion, (3) a stage of absorption, and (4) a stage of pericardial constriction. Case 4 was observed through all four stages; he was admitted with a dry pericarditis of obscure ætiology and he developed an effusion while under observation; although the effusion absorbed completely before his discharge from hospital he had signs of commencing pericardial constriction in the shape of persistent enlargement of the liver; during the ensuing three months venous distension and œdema appeared and liver enlargement increased. A pericardectomy was followed by a pleural effusion and gave no immediate relief, though there was temporary improvement two months later; nevertheless he relapsed and died six months after the operation. Case 5 illustrates an alternative course that may be followed as the disease becomes chronic. This patient developed a pericardial effusion suddenly while he was convalescent from a tuberculous pleurisy, tubercle bacilli being recovered from the pericardial fluid; the effusion gave rise to venous distension, œdema, and liver enlargement. At first it was possible to aspirate up to $500 \mathrm{ml}$. from a single puncture; but as time went on the effusion became loculated so that only a few $\mathrm{ml}$. could be obtained from any one puncture. The cardiac failure became 
chronic and he died a year after the onset of the effusion.

On the other hand, arrest and cure seem to be possible either before the development of an effusion or after its absorption. Case 6 had pericarditis without demonstrable pericardial effusion on two occasions in 1943-4: in the interval he had a rightsided pleural effusion and co-incidentally with the second attack of pericarditis he had a left-sided pleural effusion. He appears to have made a complete recovery; examination three years after the second attack failed to reveal any abnormality in the heart or lungs. Case 3 had tuberculous pleural and pericardial effusions in May 1947: he made a relatively rapid recovery, returning to work in September 1947; examination in May 1948 showed no evidence of any residual lesion. Of the more recent cases, one (Case 3) seems to have become arrested after a dry stage without effusion, and one (Case 1) shows no cardiac lesion six months after an effusion with myocardial involvement. One case was lost sight of when she was transferred to a tuberculosis hospital in accordance with service regulations. The remaining case is still under observation with a pericardial effusion which has persisted for three months.

The rapidity with which a tuberculous effusion can make its appearance is worthy of mention. Case 3 was seen one evening with pericardial friction: his apex impulse was well-defined and localized, $9 \mathrm{~cm}$. from the midline; the cardiac percussion dullness was not increased; Fig. 7 was obtained on the following forenoon when he was admitted to hospital. The rate of absorption is very variable; in Case 3 the effusion had almost completely absorbed in three weeks (Fig. 8); in Case 5 there was still effusion after eight months despite repeated aspirations.

The features of the chronic constrictive stage have been adequately described by many authors (Pick, 1896; Volhard and Schmieden, 1923; Beck, 1931; White, 1935; Hannesson, 1941; Sellors, 1946), and are outwith the scope of this article. I would agree with Ellman in suggesting that many patients with constrictive pericarditis who give no history of an acute attack have in fact had such an attack, which has been overlooked because of the mildness of the constitutional symptoms. This appears to apply with particular emphasis to those where pericarditis accompanies a primary Ghon lesion, in which subjective symptoms are particularly mild. Thus Case 2 was symptom-free. Case 1 had a pressure cough as his only subjective symptom; I have frequently heard equally severe coughs in children going about the streets, many of whom probably fail to come under medical supervision at all. I have found only one reference to pericarditis complicating an active primary Ghon lesion, and the circumstances are entirely different from those of the present cases. Seligman and Lederer (1940) describe a case in which a secondary hæmolytic streptococcal infection gave rise to an abscess that ruptured into the gland draining a Ghon focus; the gland in turn ruptured into the pericardium producing a suppurative pericarditis. The symptoms in their case were dramatic, simulating either a coronary occlusion or a perforation of an abdominal viscus; the illness was fatal.

\section{TREATMENT}

Conservative treatment has been employed in most of this series during the acute stage. One (Case 5) who had a persisting pericardial effusion with chronic cardiac tamponade, was repeatedly aspirated in addition to receiving digitalis and mercurial diuretics; he died in 12 months. One other (Case 8), an infant, has had aspiration attempted unsuccessfully; his effusion is slowly absorbing. One case was transferred elsewhere for treatment. The remaining five have been treated conservatively; two are well after 3 years and 1 year respectively; two are convalescent and free from signs of effusion or pericardial thickening after six months; one developed pericardial constriction for which operation was undertaken, but he died six months after the operation.

Treatment by aspiration and air replacement (artificial pneumo-pericardium) is being recommended by some authors; assessment of the value of this procedure will have to await more precise knowledge of the recovery rate in cases treated on purely conservative lines, a rate which would appear to be greater than has hitherto been admitted.

\section{SUMmarY}

The incidence of acute tuberculous pericarditis has been underestimated in this country hitherto. It arises in the early stage of dissemination of tuberculosis: it may be found with the primary Ghon lesion, with an apparently primary tuberculous pleurisy, or in absence of any demonstrable lung or pleural lesions. Infection of the pericardium takes place by spread from the adjacent lymph glands. Constitutiona! symptoms are mild, sometimes insufficient to lead the patient to seek medical advice; owing to the mildness of symptoms, the diagnosis is apt to be unsuspected. Evidence of myocardial involvement was obtained in one case out of eight.

The disease passes through fibrinous, effusive, and constrictive stages; but it may become arrested and apparently complete recovery may occur 
either before the development of an effusion or after its absorption. The effusion may become chronic and loculated giving rise to chronic cardiac tamponade; alternatively absorption of the effusion and apparent recovery may be followed by the development of constrictive pericarditis. The prognosis is extremely poor in cases from whose pericardial effusion tubercle bacilli are isolated; but with a sterile effusion the prognosis is hopeful. Recoveries are by no means uncommon with conservative treatment; care is therefore required in assessing claims for specific therapeutic measures.

\section{APPENDIX}

Case 1. M. aged 11. Health good till November 1947 when harsh cough developed and widespread pericardial friction found; temperature $99^{\circ}$ to $101^{\circ}$ until admission 14 days later. A sparely built,'pale youngster, alert and active, with unimpaired appetite. A harsh metallic pressure cough was his only subjective symptom throughout. Friction persisted over the entire præcordial area for 23 days in all, despite a pericardial effusion of moderate size. Serial cardiograms (Fig. 13) showed evidence of myocardial involvement. Low grade pyrexia (Fig. 12) with slight tachycardia (sleeping pulse 90 to 95). X-rays (Fig. 1 to 3) showed pericardial effusion and an active primary sub-pleural Ghon lesion in left upper lobe with enlargement of left hilar glands. Absorption of the effusion began in 4 weeks and was complete in 6 to 8 weeks; no radiological evidence of pericardial thickening remained. Venous pressure normal throughout, and signs of congestive failure absent. Ghon lesion slow in resolving and still active 6 months after admission. B.S.R. (Westergren) fell from 16 to $8 \mathrm{~mm}$. in 6 weeks, but rose again to $18 \mathrm{~mm}$. $/ \mathrm{hr}$.

Case 2. M. aged 14. Pains in metatarso-phalangeal and hip joints without sore throat or involvement of remaining joints when 11; confined to bed for several weeks. Identical attack September 1947 at age 14; mitral endocardial murmurs recognized. Referred after 8 weeks in bed. A sparely built, pale youngster, but bright, active and cheerful like Case 1, insisting that he felt perfectly well. Mid-diastolic mitral murmur and pulse 110; admitted with diagnosis of rheumatic carditis. Afebrile with sleeping pulse 80 (Fig. 10). X-ray (Fig. 4 to 6) showed active primary sub-pleural Ghon lesion in right upper lobe with hilar gland enlargement and secondary infiltration of base of right upper lobe; slight prominence of pulmonary artery and in oblique view distinct prominence of left auricle consistent with early mitral stenosis.

A week after admission pericardial friction present for four days without disturbance of pulse or temperature. Vollmer patch test positive. Absolute lymphocytosis present (W.B.C. 12400 , lymphocytes $44 \%=5500$ ). No tubercle bacilli on gastric lavage. The Ghon lesion disappeared in between 3 and 4 months. The secondary infiltration extended first, then receded. By April 1948 there remained only a small effusion in lesser fissure with slight pleural thickening; now has a typical presystolic mitral murmur but no signs of pericardial thickening. Serial cardiograms showed no characteristic abnormality.

Case 3. M. aged 27. Dysentery and quinsy in Army, but well and category A1 on demobilization February 1946. April 1947, noted attacks of slight præcordial pain and tightness, lasting half an hour at a time, but not preventing work as van driver. After 2 weeks a more severe attack with breathlessness; muffled heart sounds and elevated temperature reported by doctor. Two days later (30/4/47) pain gone, insisted he felt well, but widespread coarse pericardial friction present without cardiac enlargement or displacement of impulse; small pleural effusion present at right base. On admission next day a large pericardial effusion had developed (Fig. 7). There was never venous distension, liver enlargement or œdema. He was virtually afebrile (Fig. 11) and had no tachycardia; bradycardia during convalescence. Despite effusion pericardial friction persisted several days. Pleural fluid contained 1100 cells per cu.mm., 86 per cent lymphocytes; no tubercle bacilli seen in films; cultures sterile. Præcordial pain not severe, recurred once a week later for half an hour; otherwise he had no subjective symptoms. Absorption of pleural and pericardial effusions, began within 3 weeks and was complete in 6 weeks. Transient enlargement of the left hilar glands (Fig. 7 and 8) occurred while effusion absorbing; at this stage left auricle and pulmonary artery were prominent, and radiologist reported mitral stenosis: but there was never clinical justification for this diagnosis, and radiological appearances vanished later. Discharged from hospital end of June and resumed work September 1947. On re-examination in May 1948 no abnormality in heart or lungs, and symptom-free.

Case 4. M. aged 23. No previous illness, 2 years' active service. Coryza and cough 14 days before onset. On 10/8/41 pain across chest, breathlessness, increased severity of cough and intermittent headache; occasional vomiting. Oedema of legs developed and lasted 5 days but had subsided when admitted to E. M. S. hospital on $27 / 8 / 41$. Pericardial friction and small pericardial effusion; pulse 100 to 110 ; B.S.R. $50 \mathrm{~mm}$./hr.; afebrile. Left pleural effusion appeared a fortnight later; X-ray now reported to show " enlargement of heart with mitral configuration "; no endocardial murmurs detected at any time. Cardiogram showed R-T elevation followed by $T$ inversion in all limb leads. Pericardial effusion absorbed a month after admission, but small right-sided pleural effusion developed. By December convalescent, B.S.R. $9 \mathrm{~mm}$./hr., effusions absorbed, but liver enlargement present. Discharged from army and hospital, $17 / 12 / 41$.

Cough, breathlessness, and œdema soon recurred. Admitted to Victoria Infirmary 21/3/42 with small heart, feeble impulse, distant sounds, enlarged liver, distended neck veins, and venous pressure $24.5 \mathrm{~cm}$. Feeble cardiac pulsations on cardioscopy; prominence of pulmonary 
artery and left auricle again noted, and a second radiologist diagnosed " mitral stenosis with pericardial thickening." Pericardial resection performed by Mr. Bruce Dick on 10/4/42 was followed by jaundice, then right pleural effusion; œdema became considerable. Improvement began after a month and he was up after two months. On 6/10/42 he was convalescent and chest radiologically clear. Four days later severe pain in left chest with breathlessness and cyanosis; pleural effusion developed rapidly and he died next day with an effusion of $2300 \mathrm{ml}$. in left pleural cavity. At autopsy heart was small and there was no mitral stenosis. The excised pericardium showed tuberculous granulation tissue.

Case 5. - M. aged 43. Admitted to fever hospital in spring 1935 with bilateral pleurisy; pleural fluid and sputum positive for tubercle bacilli. Old apical scar on X-ray but no obvious fresh lesion. After 4 months, effusions absorbed, sputum negative for tubercle bacilli, no active lesion radiologically. Discharge from hospital arranged, but meantime breathlessness developed and large pericardial effusion found; aspirated several times and tubercle bacilli recovered from fluid. Transferred to Victoria Infirmary two months later; afebrile with large pericardial effusion and small pleural effusion on each side; breathless, enlarged liver, ascites, and slight œdema. Pericardium aspirated on two further occasions; no tubercle bacilli found, yet tuberculosis of larynx and palate developed 5 weeks after admission. Paroxysmal auricular fibrillation appeared, and œdema became gross requiring Southey's tubes as well as salyrgan. Oedema cleared but heart size remained unchanged and effusion was now loculated so that only 15 to $30 \mathrm{ml}$. could be withdrawn from any single puncture. Throat also improved and sputum was negative. Three months after transfer he was up and allowed home prior to entering a sanatorium where he died three months later; the circumstances of his death are not known.

Case 6. M. aged 15. History of sore throats periodically but no acute rheumatism. July 1943 fell from bicycle striking chest against pavement, but seemed none the worse after. October 1943 developed præcordial pain and fever; doctor reported cardiac irregularity; was kept in bed 3 weeks and referred a week later. A thin youngster with unhealthy tonsils, " pink and white" complexion, but no clinical signs of heart disease; heart shadow and lung fields normal radiologically; poor voltage QRS in cardiogram; B.S.R. $32 \mathrm{~mm}$./hr. Westergren. Regarded as convalescent from acute pericarditis and sent to E.M.S. hospital.

Improved slowly and B.S.R. dropped to $3 \mathrm{~mm}$. $/ \mathrm{hr}$. after 10 weeks. Tonsillectomy on $11 / 2 / 44$ followed by severe hæmorrhage requiring transfusion. On $28 / 2 / 44$ he had pain in right side of chest with fever $\left(\mathrm{T} .103^{\circ}\right)$, and signs of patchy consolidation followed by a massive effusion; the fever failed to respond to sulphonamides. The pleural fluid contained lymphocytes and polymorphs in equal numbers and was negative on examination for tubercle bacilli. After aspiration resolution was rapid; a trace of fluid remained in right costo-phrenic angle when discharged from hospital on $4 / 4 / 44$, having gained $15 \mathrm{lb}$. in weight.

Twelve days after discharge he had slight staining of sputum with tiredness, flatulence, and a little pallor; but no fresh clinical or radiological findings in heart or lungs, and weight was maintained. A month later again tired, listless, off his food, breathless, and slight cough; fainted; when next seen on $8 / 6 / 44$ pericardial friction an'd left pleural effusion found. Readmitted for 5 weeks.

Well since, though there is mild effort syndrome and occasional tendency to faint. On $30 / 10 / 47$ no abnormality in heart or lungs clinically; cardiogram physiological; on X-ray, heart shadow a little displaced to left but otherwise normal, traces of former pleurisy at left base without any remaining fluid, and slight residual fibrosis on right side. Tuberculous ætiology in this case is unproved but seems highly probable.

Case 7. F. aged 20. A girl, serving in the W.A.A.F., previously healthy, admitted with acute pleurisy; febrile and flushed with tachycardia and signs of large rightsided pleural effusion. Pericardial friction noted on admission, and pericardial effusion appeared a day or two later. Pleural exudate was lymphocytic and positive for tubercle bacilli. Transferred to a service tuberculosis hospital and further course is unknown.

Case 8. M. aged 18 months. Acute poliomyelitis at 13 months, September 1947, involving left arm and leg. Admitted orthopædic unit 29/10/47. Leg recovered during next two months but arm remained paralysed and in abduction plaster splint. Cough with signs of bronchitis noted from time to time.

February. 1948, listless and refused food; large pericardial effusion found on X-ray; no abnormality in lung fields. Transferred to medical ward under Dr. A. M. Scott. A well nourished youngster, pale, but mentally alert; heart sounds distant, no friction heard; liver enlarged, two finger-breadths below costal margin on admission, down to umbilicus six weeks later. There was no œdema, breathlessness, nor distension of neck veins. He was virtually afebrile, a temperature of $100^{\circ}$ having been recorded on two occasions and $99^{\circ}$ once; pulse 110 to 120 . Cardiogram shows low $\mathrm{T}$ waves in leads $\mathrm{I}$ and II with inverted T III, and left axial deviation. Mantoux test negative on $1 / 3 / 48$ and $26 / 4 / 48$. An attempt to aspirate pericardium on $5 / 4 / 48$ yielded blood only. $X$-ray appearances remained unaltered until 25/5/48 when commencing absorption of effusion was noted; it has now reappeared (July 1948) with œdema of arms and legs.

He is still under observation. Tuberculosis is suspected as the cause, but is as yet unproved. 


\section{REFERENCES}

Barrett, A. M., and Cole, L. (1944) Brit. Heart J., 6, 185. Norriss, G. W. (1911). Cardiac Pathology, Saunders, Beck, C. S. (1931). J. Amer. med. Ass., 97, 824.

Blalock, A., and Levy, S. E. (1937). J. Thoracic Surg., 7, 132 .

Blatt, M. L., and Greengard, J. (1928). Amer. J. Dis. Child., 35, 631 .

Clarke, J. A., Jr. (1929). Amer. J. med. Sci., 177, 115.

Ellman, P. (1945). Brit. Heart J., 7, 147.

Fine, M. J., and Katz, S. (1944). Dis. of Chest, 10, 60.

Hannesson, H. (1941). Tubercle, 22, 79.

Philadelphia.

Osler, W. (1893). Amer. J. med. Sci., 105, 20.

Pick, F. (1896). Zeit. klin med., 29, 385.

Riesman, D. (1901). Amer. J. med. Sci., 122, 6.

Rubin, E. L. (1948). Rep. proc. Liverpool med. Inst., Brit. med. J., 1, 513.

Harvey, A. M., and Whitehill, M. R. (1937). Medicine, 16,45 .

Seligman, B., and Lederer, M. (1940). New York State med. J., 40, 130.

Sellors, T. H. (1946). Brit. J. Surg., 33, 215.

Suzman, H. (1943).'Brit. Heart J., 5, 19.

Volhard, F., and Schmieden, U. (1923). Klin Woch., ii, 5.

Heimann, H.L., and Binder, S. (1940). Brit. Heart J.,2,165. White, P. D. (1935). Lancet, 2, 539 and 597. 